p- 33

Transparent Process Migration: Design Altern:tives and the Sprite Implementation

Fred Douglis and John Ousterhout

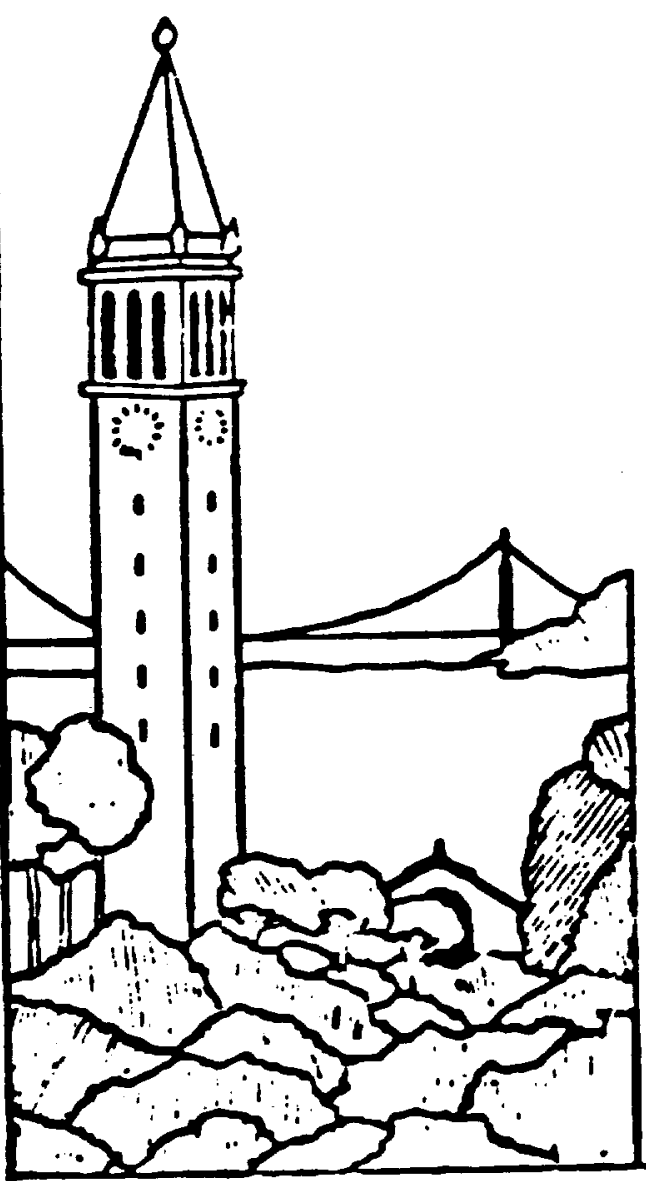

February 1991

Computer Science Division (EEC 3) University of California Berkeley, California 94720 


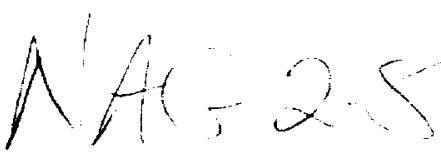

\title{
Transparent Process Migration: Design Alternatives and the Sprite Implementation*
}

\author{
Fred Douglist \\ John Ousterhout \\ Computer Science Division \\ Electrical Engineering and Computer Sciences \\ University of California \\ Berkeley, CA 94720
}

\begin{abstract}
Summary
The Sprite operating system allow execnting proceses to be moved between hi- to at any time. We use this process migration mechanism to offload work onto idle machines and also to evict migrated processes when idle workstations are reclaimed by their owners Sprite's migration mechanim provides $a$ high degree of trensparency both for migrated proces $\Rightarrow$ and for nsers. Idle mechine are identified, and eviction is in roked, antomatically by dremon nocesen. On Sprite it takes up to a few hundred millisecondo on SPARCutation 1 workntations 1 perform a remote exec, while evictions tJpically occur in a fen seconds. The pmake program remote invocation to invoke talk concurrently. Compilations commonly obtain speednp fact in in the range of three to wix; they are limited primarily by contention for centralized remourc- wach as fle servers. CPU-bound take anch a simnlations an make more effective ase of . Le bouts, obtaining as much as eightfold speedup over a period of hours. Procese migration $b$ been in regular service for over two years.
\end{abstract}

Keywords: Proceas migration, Load eharing, Operating ayotems, Distributed SyaterI , Experience

\section{Introduction}

In a network of personal worktations, many machines are typically idle at a given time. These idle hosts represent a subutantial pool of procesaing power, many times gre ter than what is available on any user's personal machine in isolation. In recent years a number f mechanims have beeri proposed or implemented to harnese idle procemore (e.g., References 1 2, 3, 4). We have implemented process migration in the Sprite operating syatem for this purpose: this paper is a description of our implementation and our experiences uning it.

By "proceas migration" we mean the ability to move a procese's execution site an an time from a source machine to destination (or target) machine of the same architocture. In p sctice, procesos migration in Sprite usually occure at two particular times. Moot often, migration bay, ens as part of

- This work we supported is part by the Defenee Advanced Resennch Projects Arency under con: set No0030-85C-0269 and in part by the National Science Foundution under grant ECS-8351961.

'Author's present addreas: Vrije Univerniteit, Dept. of Mathematio and Computer Science, De selelane 1081 an 1081 HV Amstendam, The Nethertands. Intenet: douglisOanvinl 
the exec system call when a recource-intenaive program is about to be initiated. Exec-time migration is particularly convenient because the proceas's virtual memory is reinitialized by the exee system call and thus need not be transferred from the source to the target machine. The socond common occurrence of migration is when a ueer returns to a workatation when proceanes have been migrated to it. At that time all the foreign procencen are automatically evieted beck to their home machines to minimize their impact on the returning wer's interactive reaponse.

Sprite's proces migration mechaniom provides an unuwal degree of transparency. Proces migration is almoet completely inviaible both to procenes and to weera. In Sprite, traneparency is defined relative to the home mechine for a proceas, which in the machine where the procen would have executed if there had been no migration at all. A remote process (one that bas been migrated to a machine other than its home) bas exactly the same acces to virtual memory, files, devices, and nearly all other system resourees that it would bave if it were executing on its home machine. Fusthermore, the process appears to usen as if it were etill executing on its home machine: its process identifier does not change, it appears in process listinge on the home machine, and it may be stopped, restarted, and killed just like other procenes. The only obvious sign that a process has migrated is that the load on the source machine suddenly drope and the laad on the deatination machine ouddenly increaces.

Altbough many experimental proces migration mechanims have been implemented, Sprite's is one of only a few to receive extensive practical use (other notable examples are LOCUS ${ }^{6}$ and MOSIX \%). Sprite's migration fecility has been in regular use for over two yearn. Our version of the make utility ${ }^{7}$ uses process migration automatically 20 that compilations of different fike, and other activities controlled by make, are performed concurrently. The speed-up from migration depends on the number of idle machines and the amount of parallelimm in the task to be performed, but we commonly see speed-up factors of two or three in compilations and we occasionally obtain apeed-upe as high as five or aix. In our environment, about $30 \%$ of all user activity is performed by processes that are not executing on their home machine.

In designing Sprite's migration mechanism, many alternatives were available to us. Our choice among those alternatives consisted of a tradeoff among four factora: transparency, residual dependencies, performance, and complexity. A high degree of transparency implies that procenes and users need not act differently after migration occurs than before. If a migration mechanism leaves residual dependencies (also known a "residual bost dependencies" 3\% \%), the cource machine muat continue to provide some vervices for a proceas even after the process hes migrated array from it. Residual dependencies are generally undexirable, since they impact the performance of the cource machine and make the proces vulnerable to failures of the cource. By performance, we mean that the act of migration should be efficient and that remote processes ahould (ideally) execute with the same efficiency as if they hado't migrated. Lastly, complexity is an important factor becaure proces migration tends to affect virtually every major piece of an operating syatem kernel. If the migration mechanism is to be maintainable, it is important to limit this impect $*$ much as pomible.

Unfortunately, these four factors are in conflict with each other. For example, highly-tranaparent migration mechanisms are likely to be more complicated and cause residual dependenciea. Highperformance migration mechanisms may transfer proceseses quickly at the cont of recidual dependencies that degrade the performance of remote processes. A practical implementation of migration 
must make tradeoffs among the factorn to fit the needs of its particular environme t. As will be seen in the sections below, we emphaeized transparency and performance, but accept $d$ reaidual dependencies in come situations. (See Reference $\theta$ for anotber diacueaion of the tradeof in migration, with a somewhat different result.)

A brosd apectrum of alternatives aleo exists for the policy decirions that determi : what, when, and where to migrate. For Sprite we chowe a semi-automatic appraach. The ayatem b: lpe to identify idle hoste, but it does not automatically migrate procesces except for eviction. utead, a few application programs like pmake identify long-running proceaces (perhape with uner $E$ wistance) and arrange for them to be migrated to idle machines. When users return to their macl nea, a system program automatically evicts any proceses that had been migrated onto thooe macl nes.

\section{The Sprite Environment}

Sprite is an operating asstem for a collection of personal workstations and fil cervers on a local ares network. ${ }^{10}$ Sprite's kernet-call interface in much like that of 4.3 BSD UNI , but Sprite's implementation in a new one that provides a high degree of network integration. For e ample, all the hosts on the network share a common high-performance file aystem. Procenses ma: access files or devices on any host, and Sprite allows file dats to be cached around the network whi guaranteeing the consistency of ahared acceas to files. ${ }^{11}$ Each hoat runs a distinct copy of the Sp: te kernel, but the kernels work cloeely together uning a remote-procedure-call (RPC) mechanim imilar to that described by Birrell and Nelson. ${ }^{12}$

Four aspects of our environment were particularly important in the design of $\subseteq$ rite's process migration facility:

Idle hosts are plentiful. Since our environment consists primarily of personal mack nea, it seemed likely to us that many machines would be idle at any given time For exa uple, Theimer reported that one-third of all machines were typically idle in a similar environ ent; ${ }^{3}$ Nichols reported that 50-70 worketations were typically idle during the day in an en ronment with 350 workstations totaj; 1 and our own measurements below abow 66-78\% of a worketations idle on average. The availability of many idle machines suggests that aimple Igorithms can be used for selecting where to migrate: there is no need to make complex shoices among partially-loaded machinea.

Users "own" their workstations. A user who in sitting in front of a workstat on expecte to receive the full resources of that worketation. For migration to be accepted $y$ our weers, it ceemed essential that migrated procesces not degrade interactive response. Th s suggents that a machine should only be used a a target for migration if it is known to be idle, and that foreign processes should be evicted if the ueer returns before they fininh.

Sprite uses kernel calls. Moot otber implementations of process migration are in I coeage-pasaing systems where all communication between a process and the reat of the world xecurn through message channels. In these syatems, many of the transparency apects of $\mathbf{n}$ gration can be handled simply by redirecting message communication to follow processes they migrate. 
In contrast, Sprite procemes are like UNIX procemes in that ayntem calls and other forms of interproceas communication are involed by making protected procedure calls into the kernel.

In such a syatem the solution to the transparency problem is not as obviour; in the worat case, every kernel call might have to be apecially coded to handle remote proceanea differently than local ones. We consider this insue in greater depth below.

Sprite already provides network support. We were able to capitalise on exinting mechanims in Sprite to simplify the implementation of procen migration. For example, Sprite already provided remote acceas to files and devices, and it bas a single network-wide apace of process identifiers; these features and others made it much earier to provide tranoparency in the migration mechanism. In addition, proces migration was able to we the came kernel-to-kernel remote procedure call facility that is ueed for the network file syotem and many other purpones. On SPARCatation 1 rorkatations (roughly 10 MIPS) running on a 10 megabits/eecond Ethernet, the minimum round-trip latency of a remote procedure call is about 1.6 milliseconds and the throughput is 480-660 Kbytes/second. Much of the efficiency of our migration mechaniom can be attributed to the efficiency of the underlying RPC mechaniam.

To summarize our environmental considerations, we wished to offloed work to machines whose users are gone, and to do it in a way that would not be noticed by thome users when they returned. We also wanted the migration mechaniam to work within the exirting Sprite kernel atructure, which had one potential disadvantage (kernel callo) and everal potential advantages (network-transarent facilities and a fast RPC mechaniam).

\section{Why Migration?}

Much simpler mechanisms than migration are already available for invoking operations on other machines. In order to understand why migration might be useful, consider the rah command, which provides an extremely simple form of remote invocation under the BSD verions of UNIX. Rah takes as arguments the name of a machine and a command, and causea the given command to be executed on the given remote machine. ${ }^{13}$

Rsh bas the advantages of being simple and readily available, but it lacks four important features: transparency, eviction, performance, and automatic election. First, a proces created by rah does not run in the ame environment as the parent proceas: the current directory may be different, environment variables are not tranomitied to the remote procen, and in many aystem the remote process will not have access to the ame files and devices 2 the parent proces. In addition, the urer has no direct acceas to remote processes created by reh: the processes do not appear in lintings of the urer's processes and they cannot be manjpulated unlew the user loge in to the remote machine. We felt that a mechanimm with greater transparency than rah would be eavier to use

The second problem with rah is that it does not permit eviction. A procese started by rah cannot be moved once it has begun execution. If a user returns to a machine with reh-generated procesece, then either the user must tolerate degraded response until the foreign proceses complete, of the foreign processes must be killed, which causes work to be lost and annoyance to the user who owns the foreign proceses. Nichols' butler system terminates foreign proceses after warning the user and 
providing the proceses with the opportunity to save their state, but Nichols noted $t$ at the ability to migrate existing proceses would make butler "much more pleasant to use." 1 A other option is to run foreign procesees at low priority no that a returning user receives accepts interactive response, but this would alow down the execution of the foreign procemes. It ceer $x d$ us to that everal opportunities for annoyance could be eliminated, both for the ueer whowe job are offloaded and for the user whose worketation is borrowed, by evicting foreign procemen when th: worketation's user returns.

The third problem with rah is performance. Reh usea rtandard netwock protocol with no particular kernel eupport; the overbead of eatablinhing connection, checking acceas pe mimione, and establishing an execution environment may result in delays of ceveral eeconda. $T$ is makes reh impractical for short-lived jobs and limito the speed-upe that can be obtained using : .

The final problem with rab is that it requires the wer to pick a suitable deatinatic 1 machine for offloading. In order to make offloading as convenient a possible for usere, we decidec to provide an automatic mechanism to keep track of idle machines and select deatinations for migr tion.

Of course, it is unfair to make comparisons with reh, eince some of its disad intages could be eliminated without resorting to full-fiedged process migration. For example, : ichols' bxtler layers an automatic eelection mechaniom on top of a reh-like remote execution fo ility. Several remote execution mechanisms, including butler, preserve the current directory as enviranment variables. Some UNIX systems even provide a "checkpoint/reatart" facility that per aits a process to be terminated and later recreated as a different process with the same address sace and open files. ${ }^{14}$ A combination of these approsches, providing remote invocation and che tpointing but not process migration, would offer significant functionality without the complexity $c$ a full-fledged process migration facility.

The justification for process migration, above and beyond remote invocation, is t ro-fold. First, process migration provides additional flexibility that a aystem with only remote in scation lacks. Checkpointing and restarting a long-running process is not always poesible, especiall if the process interacts with other processes; ultimately, the user would have to decide whether a process can be checkpointed or not. With transparent process migration, the system need not reatrict which processes make use of load-eharing. Second, migration is only moderately more coi plicated than transparent remote invocation. Much of the complexity in remote execution arises e $2 n$ if proceses can only move in conjunction with program invocation. In particular, if remote exec ition in transparent it turns shared atate into distributed ahared atate, which is much more diffic It to manage. The access position of a file is one example of this effech, a deacribed below in the at tion on traneferring open files. Many of the other inoues about maintaining transparency during re lote execution would also remain. Permitting a process to migrate at other times during its lifetir. $e$ requires the system to transfer additional state, such as the process's addreas space, but in not ai ificantly more complicated.

Thus we decided to take an extreme approach and implement a migration mechan im that allows processes to be moved at any time, to make that mechanism as transparent as poseib. in and to automate the selection of idle machines. We felt that this combination of features would en surage the une of migration. We also recognized that our mechanism would probably be much mori complex than rsh. As a result, one of our key criteria in choosing among implementation alternatives was simplicity. 


\section{The Overall Problem: Managing State}

The techniques ured to migrate a procen depend on the atete anociated with the process being migrated. If there existed such a thing as a atatelew procesen, then migrating such a procen would be trivial. In reality proceases have large amounts of atate, and both the amount and variety of atate ceem to be increasing a operating system evolve. The more atate, the more complex the migration mechanism is likely to be. Proces otate typically includea the following:

- Virtual memory. In terms of byter, the greatest amount of atate asociated with a process is likely to be the memory that it accesces. Thus the time to migrate a proceas is limited by the speed of transferring virtual memory.

- Open flles. If the process is manipulating files or devices, then there will be atate aeociated with these open channels, both in the virtual memory of the proceas and aleo in the operating system kernel's memory. The atate for an open file includes the internal identifier for the file, the current access position, and possibly cached file blocks. The cached file blocks may represent a substantial amount of storage, in some cases greater than the process's virtual memory.

- Message channels. In a message-based operating aystem wuch as Mach 18 or V, ${ }^{16}$ atate of this form would exist in place of open files. (In such a syotem measage channels would be uned to access files, whereas in Sprite, file-like channels are used for interproceas communication.) The state asociated with a measage channel includes buffered measeges plus information about senders and receivers.

- Execution state. This consists of information that the kernel eaves and restores during a context switch, euch as register values and condition codes.

- Other kernel state. Operating systems typically store other data acociated with a procens, such as the process's identifier, a ueer identifier, a current working directory, signal maks and handlers, resource usage statistica, references to the process's parent and children, and 20 on.

The overall problem in migration is to maintain a procese's acces to its state after it migrates. For each portion of state, the system muat do one of three thing during migration: trander the state, arrange for forwarding, or igoore the atate and acrifice traneparency. To transfer a piece of state, it must be extracted from its environment on the cource machine, transmitted to the destination machine, and reinstated in the procese's new environment on that machine. For otate that is private to the procese, such as its execution state, state transfer is relatively atraightforward. Other state, wuch a internal kernel atate distributed among complex date atructures, may be much more difficult to extract and reinatate An example of "difficult" atate in Sprite is information about open files-particularly those being acceased on remote file servers-a described below. Lantly, come state may be impossible to transfer. Such state is woually asociated with physical devices on the source machine. For example, the frame buffer associated with a dioplay must remain on the machine containing the display; if a process with acceas to the frame buffer migratea, it will not be possible to transfer the frame buffer. 
The aecond option for each piece of atate in to arrange for forwarding. Rather the I transfer the state to atay with the proceas, the aystem may leave the atate where it is and forw id operations back and forth between the atate and the procean. For example, $1 / O$ devices cannot 1 tranaferred, but the operating aystem can arrange for output requeats to be paased back from the rocew to the device, and for input data to be forwarded from the device's machine to the process. In the case of message channele, arranging for forwarding might consiat of changing eender and rece ver addresacs wo that messages to and from the channel can find their way from and to the prr eas. Ideally, forwarding should be implemented tranoparently, wo that it in not obvious outside he operating system whether the state wa tranferred or forwarding was arranged.

The third option, acrificing transparency, is a last resort: if neither atate transfer : or forwarding is feasible, then one can ignore the state on the cource machine and simply use the orreopoading state on the target machine. The only wituation in Sprite where neither otate transfer or forwarding seemed reasonable is for memory-mapped I/O devices web as frame buffers, a allude I to above. In our current implementation, we disallow migration for processes using these devices.

In a few rare cases, lack of transparency may be deairable. For example, a proces that requests the amount of physical memory available ahould obtain information about ite curre $t$ hoot rather than its home machine. For Sprite, a fer apecial-purpose kernel calls, euch as to read if trumentation counters in the kernel, are also intentionally non-transparent with respect to migrati $\mathrm{D}$. In general, though, it would be unfortunate if a procese behaved differently after migration thas before.

On the surface, it might appear that mesage-baeed aystems like Accent, ${ }^{17}$ Che otte, or V 16 simplify many of the atate-management problems. In these syetems all of a procen interections with the rest of the world occur in a uniform fashion through memage channels. execution state of a process bas been migraled, it would reem that all of the remaini $g$ ineues could be solved simply by forwarding measages on the process's mesage channels. The mese fe forwarding could be done in a uniform fashion, independent of the servers being communicate with or their state about the migrated process.

In contrast, atate management might ceem more difficult in a syotem like Sprit = that is baced on kernel calls. In such a eystem moet of a process's cervices must be provided b the kernel of the machine where the process executes. This requires that the atate for each service be traneferred during migration. The state for each service will be different, $\infty$ this approach wo Id reem to be much more complicated than the uniform measage-forwarding approach.

It turns out that neither of these initial impressions is correct. For example, it $\nabla c$ Id be pascible to implement forwarding in a kernel-call-based aystem by leaving all of the kernel at : $:$ on the home machine and using remote procedure call to forward home every kernel call. ${ }^{14}$ This ould result in comething very similas to forwarding mesagee, and we initially uned an approach bikt this in Sprite.

Unfortunately, an approach based entirely on forwarding kernel calle or forwardin meangen will not work in practice, for two reacons. The firat problem is that some services must neceacarily be provided on the machine where a procese is executing. If a procese invokes a kernel all to allocate virtual memory (or if it eends a meseage to a memory server to allocate virtual memo: $f$ ), the requeat must be processed by the kernel or cerver on the machine where the procese exec: tea, since only that kernel or server has control over the machine's page tables. Forwarding is not viable option for such machine-specific functions: state for these operations must be migrated rith processes. 
The second problem with forwarding is coat. It will often be much more expensive to forward an operation to eome other machine than to process it bocally. If a cervice in available beally on a migrated process's new machine, it will be more efficient to use the local service then to formard operations back to the cervice on the procean's old machine.

Thus, in practice all syntem must tranefer substantial amounte of atate a part of process migration. Measage-based rystem make migration comewhat aasier than kernel-call-based ayotems, because come of the atate that in maintained by the kernel in a kernel-call-baced system is maintained in a process's address space in a memage-based ayntem. This atete is tranoferred implicitly with the addreas apace of the procese. For other atate, both types of system must addreas the came insues.

\section{Mechanics of Migration}

This section describes how Sprite deals with the various components of proces state during migration. The solution for each component consists of some combination of transferring state and arranging for forwarding.

\section{Virtual Memory Transfer}

Virtual memory transfer is the appect of migration that has been diecuased the moat in the literature, perhaps because it is generally believed to be the limiting factor in the apeed of migration. ${ }^{17}$ One simple method for transferring virtual memory is to send the procese's entire memory image to the target machine at migration time, 20 in Charlotte ${ }^{\circ}$ and LOCUS. ${ }^{6}$ This approach is simple but it has two disadvantages. Firat, the tranofer can take many coconde, during which time the process is frozen: it cannot execute on either the cource or deatination machine. For come procences, particularly those with real-time needs, long freese times may be unacceptable. The recond disadvantage of a monolithic virtual memory tranofer is that it may reault in wasted work for portions of the virtual memory that are not ued by the proces after it migratea. The extra work is particularly unfortunate (and coatly) if it requires old pages to be read from secondary storage. For these reacons, eeveral other approaches have been used to reduce the overhead of virtual memory tranefer; the mechanisms are diagrammed in Figure 1 and deacribed in the paragraph below.

In the V System, long freese times could have reaulted in timeouta for proceases trying to communicate with a migrating proces. To addrea this problem, Theimer ueed a method called grecopying. 3 - Rather than freezing a proces at the beginning of migration, $\mathrm{V}$ allows the proces to continue executing while its addreas space is transferred. In the original implementation of migration in $V$, the entire memory of the procese wae transferred directly to the target; Theimer also proponed an implementation that would use virtual memory to write modified pages to a shared "becking storage server" on the network. In either case, come pages could be modified on the source machine after they have been copied eloewhere, $10 \mathrm{~V}$ then freezes the procea and copies the pagea that have been modified. Theimer showed that pre-copying reduces freese times subetantially. However, it has the disadvantage of copying come pages twice, which increases the total amount of work to migrate a process. Pre-copying seems most useful in an environment like $V$ where processes have real-time response requirements. 


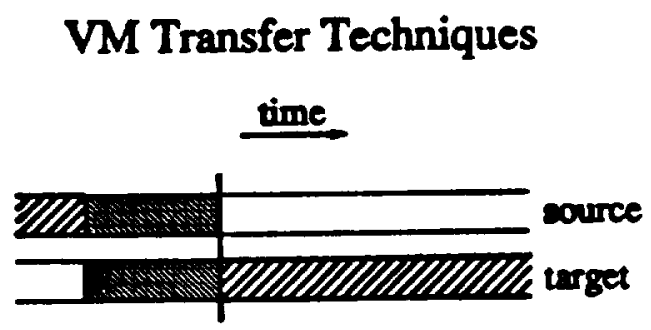

(a) LOCUS, Charlotte

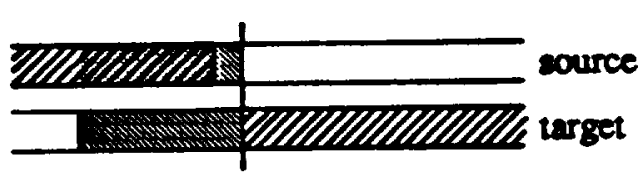

(b) $\mathrm{V}$

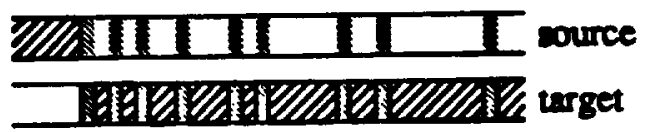

(c) Accent

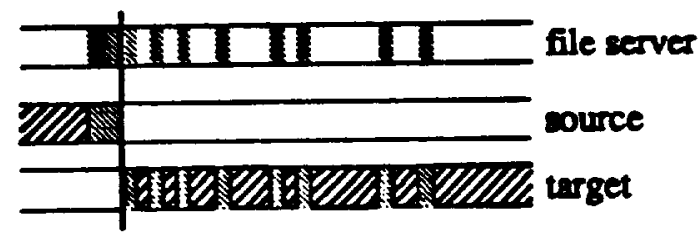

(d) Sprite

WIIA process executes

transfer virtual memory

residual dependencies end

Figure 1: Different technigues for tronsferring virtual memory. (a) ahows the acheme uned a LOCUS and Charlotte, where the entire addreas opece is copied at the time a proces migntes. (b) show she pre-copring scheme used in V, where the virtual memory is tranderred during migration but the proces continnes to execute during moat of the trannfer. (c) abowe Acceat's lasy-copsing approach, where paE 3 are retrieved from the cource machine a they are referenced on the terget. Recidual dependencies in Acent can hat for

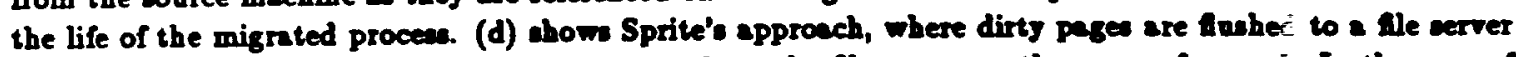
during migration and the target retrieves pages trom the flle cerver a thes are referencec ${ }^{z}$ In the case of eviction, there are no residual dependencies on the cource ather mignation. When a proce- migretes amy from its home machine, it has residual dependencies on its home throughout its lifetime. 
The Accent system uses a lary copying apprasch to reduce the cont of procese migrations 17 When a proces migrates in Accent, its virtual memory pages are left on the source machine until they are actually referenced on the target machine. Pages are copied to the target when they are referenced for the first time. This approach allowe a procen to begin execution on the target with minimal freeze time but introduces many ahort delays later 2 pages are retrieved from the cource machine. Overall, laxy copying reduces the cost of migration because page that are aot weed are never copied at all. Zaya found that for typical programe only coe-quarter to coe-half of a proceas's allocated memory needed to be traneferred. One disadvantage of lacy copying is that it leavea residual dependencies on the cource machine: the cource mut store the unreferenced pages and provide them on demand to the target. In the wornt case, a proceas that migrates everal times could leave virtual memory dependencies on any or all of the hoots on which it ever executed.

Sprite's migration facility uses a different form of lacy copying that takes advantage of our exiating network nervices while providing come of the advantages of lary copying. In Sprite, $\omega$ in the propoced implementation for $V$, backing storage for virtual memory is implemented uning ordinary filea. Since these backing files are atored in the network file gyotem, they are acceasible throughout the network. During migration the source machine freeses the procean, flubes its dirty pages to backing filea, and discards its address space. On the target machine, the process starts executing with no reaident pages and uses the standard paging mechanimm to load pages from backing files at they are needed.

In most cases no disk operations are required to flush dirty pagen in Sprite. This is bocause the backing files are stored on network file cerven and the file eervers use their memories to cache recently-used file data. When the cource machine flushes a dirty page it is simply transerred over the network to the werver's main-memory file cache. If the deatination machine acceases the page then it is retrieved from the cache. Disk operations will only occur if the server's cache overflows.

Sprite's virtual memory transfer mechanism was simple to implement because it uece pre-existing mechanisms both for flushing dirty pages on the cource and for handling page faults on the target. It has some of the benefits of the Accent laxy-copying approsch since only dirty pages incur overhead at migration time; other pages are eent to the target machine when they are referenced. Our approach will require more total work than Accent's, though, since dirty pages may be transferred over the network twice: once to a file eerver during fushing, and once later to the destination machine.

The Sprite apprasch to virtual memory tranofer fits well with the way migration is typically ured in Sprite. Process migration occure moat often during an ezec ayetem call, which completely replaces the process's address space. If migration occurs during an exee, the ner addren space in created on the destination machine so there in no virtual memory to tranefer. As other have obwerved (e.g., LOCUS ${ }^{5}$ ), the performance of virtual memory tranofer for ezec-time migration is not an imue. Virtual memory transfer is an isue, bowever, when migration is used to evict a procen from a machine whose user has returned. In this situation the moat important consideration in to remove the proces from its cource machine quickly, in order to minimise any performance degradation for the returning ueer. Sprite's approach worke well in thie regand aince (a) it does the leant poavible work to free up the source's memory, and (b) the cource need not retain pages or respond to later paging requests as in Accent. It would have been more efficient overall to tranofer the dirty pages directly to the target machine instead of a file server, but this approach would have added complexity to the migration mechanism so we decided against it. 
Virtual memory transfer becomes much more complicated if the proceas to be mig thed is aharing writable virtual memory with some other proces on the cource machine. In principl, it is pomible to maintain the shared virtual memory even after one of the aharing procence migr-tea, 18 but this changes the cost of ehared accences 20 dramatically that it neemed unreneonable 0 us. Shared writable virtual memory almost never occurs in Sprite right now, so we simply dise on migration for procesces uning it. A better long-term colution is probably to migrate all the ah ing proceases together, but even this may be impractical if there are complex patterns of ahari: 3 that involve many proceseces.

\section{Migrating Open Files}

It turned out to be particularly difficult in Sprite to migrate the state asocis. ed with open files. This was surprising to us, because Sprite already provided a highly transpart $t$ network file system that supports remote access to files and devices; it aleo sllow files to be ached and to be eccessed concurrently on different workstations. Thus, we expected that the $z$ zration of filerelated information would mostly be a matter of reuning existing mechanisme. Unfortl ately, process migration introduced new problems in managing the distributed state of open filea. Nigration aleo made it possible for a file's current access position to become shared among several sachines.

The migration mechaniam would have been much aimpler if we had choeen th: "arrange for forwarding" approach for open files instead of the "transfer atate" approsch. $T$ is would have implied that all file-related kernel calls be forwarded back to the machine where the the waped, so that the state aseociated with the file could have atayed on that machine. Because $c$ the frequency of file-related kernel calls and the coot of forwarding a kernel call over the network, $t$ felt that this approach would be unacceptable both because it would alow down the remote proce and because it would load the machine that stores the file state. Sprite workstations are typica $y$ diskeas and files are accessed remotely from file servers, 20 the forwarding apprasch would have $x$ eant that each file request would be passed over the network once to the machine where the file wopend, and possibly a eecond time to the cerver. Instead, we decided to tranafer open-file ots a along with a migrating proceas and then use the normal mechaniems to access the file (i.e., comm nicate directly with the file's server).

There are three main components of the state associated with an open file: a file re. srence, caching information, and an acceas position. Each of these componente introduced probler for migration. The file reference indicates where the file is stored, and aleo provides a guarantee th the file exiats (as required by UNIX memantica): if a file is deleted while open then the deletion deferred until the file is closed. Our first attempt at migrating files simply closed the file on the ource machine and reopened it on the target. Unfortunately, this approsch cauned files to dieapp ar if they were deleted before the reopen completed. Thin is such a common occurrence in UNIX PI grame that file transfer had to be changed to move the reference from cource to target without eve: cloaing the file.

The second component of the atate of an open file in caching information. Sp te permits the data of a file to be cached in the memory of one of more machines, with file servers responsible for guaranteeing "consistent access" to the cached data "The server for a file keeps trac of which hosts have the file open for reading and writing. If a file is open on more than one host an at least one of 
them is writing it, then caching is dieabled: all hoote muat forward their read and write requeats for that file to the server 20 they can be serialized. In our second attempt at migrating files, the cerver was notified of the file's use on the target machine before being told that the file wos no longer in use on the source; this made the file appear to be write-ehared and caued the server to disable caching for the file unnecesuarily. To colve both this problem and the reference problem above we built opecial server code juat for migrating flea, wo that the transfer from cource to deatination in made atomically. Migration can atill cause caching to be disabled for a file, but only if the file in aloo in wee by wome other proces on the cource machine; if the only use in by the migrating procen, then the file will be cacheable on the target machine. In the current implementation, once caching in dieabled for a file, it remaine disabled until no procem has the file open (even if all procemes accescing the file migrate to the came machine); however, in practice, caching is disabled infrequently enough that an optimization to reenable caching of uncacheable files bas not been a high priority.

When an open file is transferred during migration, the file cacbe on the cource machine may contain modified blocks for the file. These blocks are flushed to the file's server machine during migration, $\infty$ that after migration the target machine can retrieve the blocks from the file cerver without involving the source. This approsech is aimilar to the mechanimm for virtual memory tranefer and thus has the same advantages and dieadvantages. It is aleo similar to what happens in Sprite for shared file access without migration: if a file is opened, modified, and cloned on one machine, then opened on another machine, the modified blocks are fluhed from the firat machine's cache to the server at the time of the second open.

The third component of the state of an open file is an acceas poaition, which indicates where in the file the next read or write operation will occur. Unfortunately the acceas position for a file may be shared between two or more proceses. This happens, for example, when a proces opens a file and then forks a child procese: the child inherits both the open file and the acceas position. Under Dormal circumstances all of the procesoes sharing a aingle access pocition will reaide on the same machine, but migration can move one of the proceanes without the othere, 20 that the acceas position becomes shared between machines. After several false starts we eventually dealt with this problem in a fashion similar to caching: if an acceas porition becomes shared between machines, then neither machine stores the accea position (nor do they cache the file); instead, the file's server maintains the access position and all operations on the file are forwarded to the cerver.

Another possible approsech to shared file offects in the one used in LOCUS! If proceas migration causes a file acces position to be abared between machines, LOCUS lets the aharing machines take turns managing the access position. In order to perform I/O on a file with a shared access position, a machine must acquire the "acces position token" for the file. While a machine has the acceas position token it caches the accese position and no other machine may accen the file. The token rotates among machines as needed to give each machine accen to the file in turn. This approsch is similar to the approach LOCUS ures for managing a shared file, where cliente take turna caching the file and pase read and write tokens around to ensure cacbe consintency. We chose not to une the Locus approach because the token-pasing approach i more complex than the disable-caching appraech, and because the disable-caching approach meshed better with the existing Sprite file ayotem.

Figure 2 shows the mechanism currently ueed by Sprite for migrating open filea. The key part of this mechanism occure in a late phase of migration when the target machine requeats that the 


\section{Transferring Open Files}

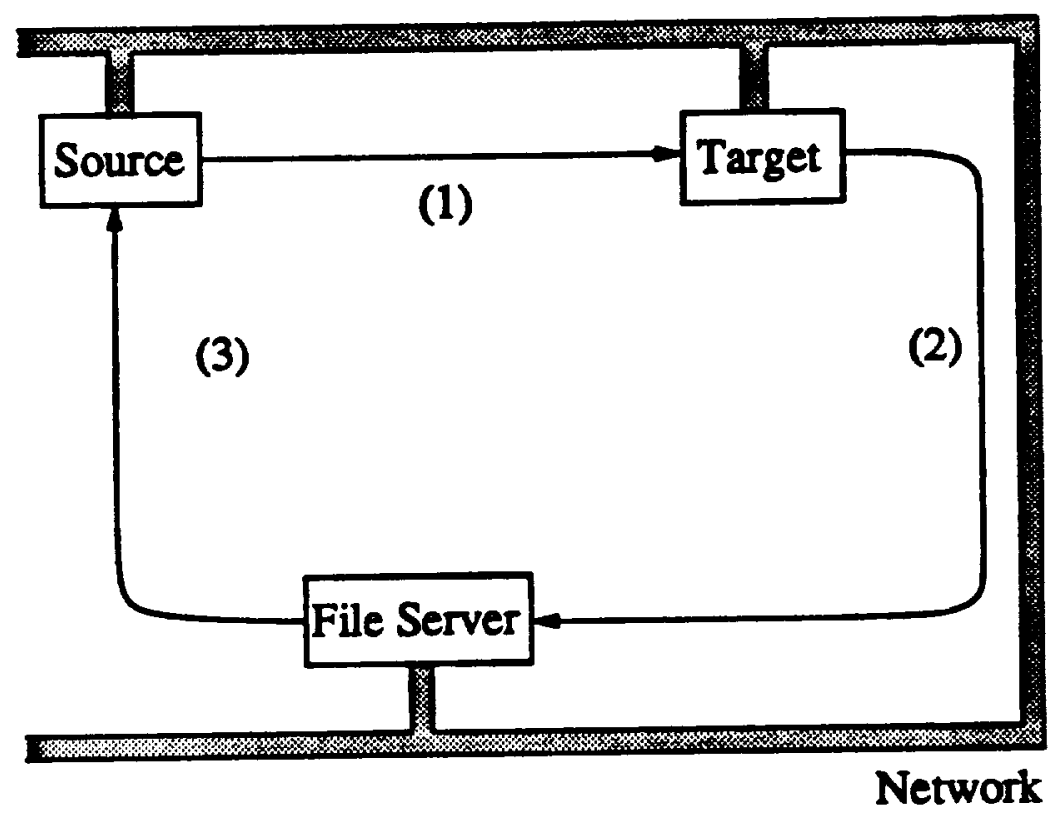

Figure 2: Transferring open files. (1) The source pasces information abont all open fll .- to the target. (2) For each file, the target notifies the server that the open fle ba been moved; (3) dai 18 this all the erver communicates again with the conrce to release its state ascociated with the file and to btain the most recent otale asoocinted with the file.

server update its internal tables to reflect that the file is now in wee on the target instead of the source. The server in turn calls the source machine to retrieve information about $t$ ie file, such as the file's access position and whether the file in in use by other proceseses on the $t$ urce machine. This two-level remote procedure call synchronizes the three machines (source, tare $t$, and server) and provides a convenient point for updating state about the open file.

\section{The Process Control Block}

Aside from virtual memory and open files, the main remaining inue is how th deal with the process control block (PCB) for the migrating proces: should it be left on the sol ce machine or transferred with the migrating proceas? For Sprite we use a combiaation of both a proaches. The home machine for a proceas (the one where it would execute if there were no migrat: na) munt axiat in some operations on the procese, 0 it always maintains a PCB for the procese. Th details of this interaction are deacribed in the next rection. In addition, the current machine for a roceas aleo bas a PCB for it. If a process is migrated, then moat of the information about the proce: is kept in the PCB on its current machine; the PCB on the home machine eerves primarily to lo the the process and most of its fields are unused. 
The other elements of proces atate besides virtual memory and open files are much easier to transfer than virtual memory and open filea, aince they are not $\boldsymbol{m}$ bulky $\boldsymbol{\omega}$ virtual memory and they don't involve distributed atate like open files. At present the other state connists almost entirely of fields from the process control block. In general, all that need to be done is to tranofer these fields to the target machine and reinstate them in the process control block on the target.

\section{Supporting Transparency: Home Machines}

As was mentioned previoualy, tranoparency was one of our moot important gaals in implementing migration. By "transparency" we mean two thinge in particular. Finth a procese's behavior ahould not be affected by migration. Its execution environment should appear the came, it ahould have the ame access to nystem resources auch a files and devices, and it should produce exactly the anme results as if it hadn't migrated. Second, a proceas's appearance to the reat of the world ahould not be affected by migration. To the reat of the world the process should appear an if it never left its original machine, and any operation that is poasible on an unmigrated proces (auch as atopping or signalling) should be possible on a migrated proces. Sprite provides both of these forms of transparency; we know of no other implementation of process migration that provides transparency to the same degree.

In Sprite the two appects of transparency are defined with reapect to a procen's home mechine, which is the machine where it would execute if there were no migration at all. Even after migration, everything should appear as if the process were etill executing on it home machine. In order to achieve transparency, Sprite uses four different techniquee, which are described in the paragraphs below.

The most desirable approach is to make kernel calls location-independent; Sprite has been gradually evolving in this direction. For example, in the early versions of the system we permitted different machines to have different views of the file aystem name space. This required open and several other kernel calls to be forwarded home after migration, imponing about a $20 \%$ penalty on the performance of remote compilations. In order to aimplify migration (and for ceveral other good reasons also), we changed the file system 20 that every machine in the network nees the came name space. This made the open kernel call location-independent, 0 no extra effort was neceacary to make open work transparently for remote proceseen.

Our eecond technique was to transfer state from the cource machine to the target at migration time as described above, wo that normal kernel calls may be ued after migration. We uned the state-transfer approach for virtual memory, open files, procese and user identifiers, resource uage atatistics, and a variety of other thinge.

Our third technique was to forward kernel calls home. This technique was originally ueed for a large number of kernel calls, but we have gradually replaced moat unes of forwarding with traneparency or stete tranefer. At present there are only a few kernel call that cannot be implemented transparently and for which we cannot easily transfer atate. The moet important such kernel call in gettimeofday, which returns the current time. Clocks are not aynchronized between Sprite machines, wor remote processes Sprite forwards the gettimeofdey kernel call back to the home machine. This guarantees that time advances monotonically even for remote procesesa, but incurs a performance 
penalty for processes that read the time frequently.

Forwarding also occurs from the home machine to a remote process's current sachine. For example, when a process is signalled (c.g., when come other procese specifies its ident fier in the kill kernel call), the aignal operation is sent initially to the procese's home machine. If the rocess in not executing on the home machine, then the home machine forwards the operation on the procese's current machine. The performance of auch operations could be improved by retain a cache on each machine of recently-used process identifiers and their last known execution sitea. This approach is ueed in LOCUS and V and allows many operations to be sent directly to a remote $p$ sceas without passing through another host. An incorrect execution aite is detected the next time it is uned and correct information is found by sending a mesaage to the hoot on which the proce + wa created (LOCUS) or by multi-casting (V).

The fourth "approach" is really just a set of ad hoe techniques for a fer kernel a lls that must update state on both a process's current execution site and its home machine. C te example of such a kernel call is fork, which creates a new process. Process identifiers in Spri e consist of a home machine identifier and an index of a process within that machine. Managen at of process identifiers, including allocation and deallocation, is the responsibility of the home mact nes named in the identifiers. If a remote process forts, the child process must have the same bome sachine as the parent, which requires that the bome machine allocate the new proces identifier. Fu thermore, the bome machine must initialize its own copy of the proces control block for the proces, a deacribed previously. Thus, even though the child process will execute remotely on the an machine as its parent, both its current machine and its home machine muat update state. $S$ nilar kinds of cooperation occur for exit, which is invoked by a process to terminate iteelf, and wait which is weed by a parent to wait for one of its children to terminate. There are several potential sce conditions between a process exiting, its parent waiting for it to exit, and one or both processet migrating; we found it easier to aynchronize these operations by keeping all the state for the wait-r at rendervous on a single machine (the home). LOCUS similarly ubes the aite on which a procet is created to synchronize operations on the process.

\section{Residual Dependencies}

We define a residual dependency as an on-going need for a hoot to maintain dat structures or provide functionality for a procese even after the proces migrates away from the hoo One example of a residual dependency occurs in Accent, where a procese's virtual memory pages ire beft on the cource machine until they are referenced on the target. Another example occurs i Sprite, where the bome machine must participate whenever a remote proces forks or exits.

Residual dependencies are undesirable for three reasons: reliability, performance, \pm ad complexity. Residual dependencies decrease reliability by allowing the failure of one bout to t Fect proceses on other hosts. Residual dependenciea decreace performance for the remote proce $;$ becaure they require remote operations where beal ones would other wive have sufficed. Residu $=$ dependencies also add to the load of the hoat that is depended upon, thereby reducing the perfoi nance of other processes executing on that host. Lastly, residual dependencies complicate the systerr by distributing a process's state around the network instead of concentrating it on a single host; a I rticularly bed 
ccenario is one where a procen can migrate several timea, leaving reaidual dependenciea on every host it has visited.

Despite the disadvantages of residual dependencies, it may be impractical to eliminate them all. In some cases dependencies are inherent, wuch as when a procese is uring a device on a apecific host; these dependencies cannot be eliminated without changing the behavior of the proceas. In other cases, dependencies are neceasary or convenient to maintain transparency, euch as the bome machine knowing about all process creations and terminations. Lantly, revidual dependenciec may actually improve performance in some caves, such a lasy copying in Accent, by deferring state tranifer until it is abeolutely neceseary.

In Sprite we were much more concerned about transparency than about reliability, wo we permitted come residual dependencies on the home machine where those dependencies made it earier to implement transparency. As deacribed above in the ection on tranaparency, there are only a few situations where the home machine must participate 20 the performance impact in minimal Measurements of the overhead of remote execution are reported below.

Although Sprite permite residual dependencies on the home machine, it does not kave dependencies on any other machines. If a procese migrates to a machine and in then evicted or migrates away for any other reason, there will be no residual dependencies on that machine. This provides yet another assurance that process migration will not impact users' response when they return to their workstations. The only noticeable long-term effect of foreign proceses is the rewources they may have utilized during their execution: in particular, the user's virtual memory working ret may have to be demand-paged back into memory upon the ueer's return.

The greatest drawback of residual dependencies on the home machine in the inability of ureers to migrate processes in order to survive the failure of their bome machine. We are considering a nontransparent variant of procese migration, which would change the home machine of a process when it migrates and break all dependencies on its previous hoat.

\section{Migration Policies}

Until now we have focussed our discusaion on the mechanisms for transferring proceases and supporting remote execution. This ection considers the policies that determine hor migration is used. Migration policy decisions fall into four categorien:

What. Which processes should be migrated? Should all procences be considered candidates for migration, or only a few particularly CPU-intensive proceseces? How are CPU-intensive procenses to be identified?

When. Should processes only be migrated at the time they are initiated, or may proceaces also be migrated after they have been running?

Where. What criteria should be weed to select the machines that will be the targets of migration?

Who. Who makes all of the above decisions? How much abould be decided by the ueer and how much should be automated in ryatem software? 
At one end of the policy epectrum lies the pool of processors model. In this model is ie proceasors of the aystem are treated as a ahared pool and all of the above decivions are made : utomatically by system software. Users submit jobs to the gystem without any idea of where they will execute. The system assigns jobs to proceseors dynamically, and if proces migration is ave lable it may move processes during execution to belance the loads of the procesears in the pool. M SSIX ${ }^{6}$ is one example of the "pool of proceseore" model proceseors are shared equally by all proc aes and the cystem dynamically balances the load throughout the system, uing procem migratio:

At the other end of the policy opectrum lies rah, which provides no policy suppor whateover. In this model individual users are responsible for locating idle machines, negotiating wi th other users over the use of those machines, and deciding which procemes to offload.

For Sprite we chose an intermediate approach where the selection of idle bosts is fi: ly automated but the other policy decisions are only partially eutomated. There were two reasons fo: this decision. First, our environment consists of personal worketations. Users are heppy runoing alm all of their processes locally on their own pereonal workstatione, and they expect to have comp the control of their workstations. Users do not think of their workstations as "abared". Second, the ynamic poolof-processors approach appeared to us to involve considerable edditional complexity and we were not convinced that the benefits would justify the implementation difficulties. For a ample, most processes in a UNIX-like environment are 20 ohort-lived that migration will not produ: : a noticeable benefit and may even slow things down. Eager et al. provide additional evidence the migration is only useful under particular conditions. ${ }^{10}$ Thus, for Sprite we decided to make migr - ion a special case rather than the normal case.

The Sprite kernels provide no particular support for any of the migration policy lecisions, but user-level applications provide asistance in four forms: idle-boat eelection, the pme e program, a mig shell command, and eviction. These are discussed in the following subeections.

\section{Selecting Idle Hosts}

Each Sprite machine runs a background process called the loed-everage daemon, : hich monitors the usage of that machine. When the workstation appears to be idle, the load-average $c$ semon notifies the central migration server that the machine is ready to accept migrated proces . Programs that invoke migration, such as pmake and mig deacribed below, call atandard lib ury procedure Mig_RequestIdleBosts to obtain the identifiers for one or more idle boste, which the then pase to the kernel when they invoke migration. Normally only one procea may be assign 1 to any hoat at any one time, in order to avoid contention for proceseor time; however, proceser i that requeat idle bosts can indicate that they will be executing long-running proceses and the ces iral cerver will permit sborter tasks to execute on thowe hosto as well.

Maintaining the database of idle boete can be a challenging problem in a distr suted system, particularly if the aystem is very large in size or if there are no shared facilities avail ble for storing lasd information. A number of distributed algorithm have been proposed to wolv this problem, such as disseminating losd information among bosts periodically, ${ }^{6}$ querying other $\mathbf{b}$ ste at random to find an idle one, ${ }^{20}$ or multicasting and accepting a response from any host that adicatea avaitability. 
In Sprite we bave used centralized approsches for atoring the idle-host database. Centralized techniques are generally simpler, they permit better decioions by keeping all the information upto-date in a single place, and they can ecale to syatems with bundreds of workstations without contention problems for the centralized database.

We initially stored the database in a single file in the file syntem. The load-average daemons set flags in the file when their hosts became idle, and the Mig_RegrentJlleBosts library procedure selected idle hosts at random from the file, marking the selected honts 20 that no one else would select them. Standard file-locking primitives were used to aynchronire socese to the file.

We later switched to a server-besed approach, where a single eerver process keepo the database in its virtual memory. The load-average deemons and the Mig_ReguestJdleBosts procedure communicate with the server using a message protocol. The server approsch has a number of advantages over the file-based approach. It is more efficient, because only a mingle remote operation is required to select an idle machine; the file-based approach required eeveral remote operation to open the file, lock it, read it, etc. The server approach makes it eary to retain state from request to request; we use this, for example, to provide fair allocation of idle hosts when there are more would-be users than idle machines. Although some of these features could have been implemented with a ahared file, they would incur a high overhead from repeated communication with a file erver. Lantly, the server approach provides better protection of the database information (in the shared-file approach the file had to be readable and writable by all ueers).

We initially chose a conservative set of criteria for determining whether a machine is "idle". The losd-average daemon originally considered $a$ hoat to be idle only if (a) it had had no keyboard or mouse input for at least five minutes, and (b) there were fewer runnable procenes than proceanors, on average. In choosing these criteria we wanted to be certain not to inconvenience active ubers or delay background proceses they might have left running. We ansumed that there would unually be plenty of idle machines to go around, $\infty$ we were lese concerned about using them efficiently. After experience with the five-minute threshold, we reduced the threshold for input to 30 reconds; this increased the pool of available machines without any noticeable impact on the owners of those machines.

\section{Pmake and Mig}

Sprite provides two convenient waye to use migration. The mont common use of proces migretion is by the pmake program. Pmake is aimilar in function to the make UNIX utility and in used, for example, to detect when cource files have changed and recompile the correaponding object files. Make performs its compilations and other actions serially; in contrant, pmeke uses proces migration to invoke as many commands in parallel as there are idle hoats available. This use of process migration is completely transparent to ueere and results in oubatantial speed-upe in many situations, as shown below. Other systems besides Sprite have aleo benefitted from parallel make facilitien; wee References 21 and 2 for examples.

The approach used by pmake has at least one advantage over a fully-automatic "proceasor pool" approach where all the migration decisions are made centrally. Because pmake makes the choice of processes to offlosd, and knows bow many bosts are available, it can acale its parallelism to match 
the number of idle hoats. If the offloading choice were made by come other agent, make might overload the system by creating more proceses than could be accommodated effici ntly. Pmake also provides a degree of flexibility by permitting the wer to apecify that certain tas a ahould not be offloaded if they are poorly suited for remote execution.

The second eany way to use migration is with a program called mig, which takes argument a shell command. Mig will relect an idle machine uning the mechanism deacribed rove and use process migration to execute the given command on that machine. Mig may aloo be $u$ if to migrate an existing process.

\section{Eviction}

The final form of aystem support for migration is eviction. The load-average ds mons detect when a user returns. On the first keyatroke or mouse-motion invoked by the user, th loed-average daemon will check for foreign proceseses and evict them. When an eviction occurs, for ign processes are migrated back to their home machines, and the procese that obtained the hoet $i$ notified that the host bas been reclaimed. That proces in free to remigrate the evicted processes $x$ to surpend them if there is no new host available. To date, pmake is the only application that utomatically remigrates processes, but other applications (euch as mig) could remigrate proceases well.

Evictions also occur when a bost is reclaimed from one proces in order to allocate it to another. If the centralized server receives a requeat for an idle boat when no idle hosts are ave able, and one process has been allocated more than its fair share of boats, the eerver reclaim or of the hosts being used by that process. It grants that host to the process that had received les 3 than its fair share. The process that lost the bost must reduce its parallelism until it can obtain a ditional hosts again.

A possible optimization for evictions would be to permit an evicted procese to mig: ite directly to a new idle bost rather than to its home machine. In practice, half of the evictions th $: 3$ occur in the system take place due to fairness considerations rather than because a user has retu aed to an idle workstation. ${ }^{22}$ Permitting direct migration between two remote houts would benefit the other half of the evictions that occur, but would complicate the implementation: it would requi $\&$ three-way communication between the two remote hosts and the home machine, which always 1 ows where its processes execute. Thus far, this optimization has not seemed to be warranted.

\section{Performance and Usage Patterns}

We evaluated process migration in Sprite by taking three eets of meanurements. The next rubrections discuss particular operations in isolation, such os the time to migrate a tri ial process or invoke a remote command; the performance improvement of pmake using parallel rer ste execution; and empirical measurements of Sprite's process migration facility over \& period of we: sral weeke, including the extent to which migration is used, the coet and frequency of evietion, and he availability of idle hosts. 


\begin{tabular}{|c|c|}
\hline Action & Time/Rate \\
\hline Select \& release idle host & 36 milliseconds \\
\hline $\begin{array}{l}\text { Migrate "null" process } \\
\text { Transfer info for open files } \\
\text { Flush modified fle blocks } \\
\text { Flush modified pages } \\
\text { Transfer ezee argument. }\end{array}$ & $\begin{array}{l}76 \text { milliseconds } \\
9.4 \text { millieceonds/file } \\
480 \mathrm{Kbytes} / \text { eccond } \\
660 \mathrm{Kbytes} / \text { eccond } \\
480 \mathrm{Kbytes} / \text { eccond }\end{array}$ \\
\hline $\begin{array}{l}\text { Fork, exec null process with migration, wait for child to exit } \\
\text { Fork, exec null process locally, wait for child to exit }\end{array}$ & $\begin{array}{l}81 \text { milliseconds } \\
46 \text { milliseconds }\end{array}$ \\
\hline
\end{tabular}

Table 1: Costs associated with process migration. All measurements were performed on SPARCatation I workstations. Hoat eelection may be amortised scroas neveral migntions if applications ench a pmake reuse idle hosts. The time to mignte a procen depends on how many open tlles the procen has and how many modified blocks for thowe files are cached bocully (these mant be luabed to the werver). Ir the mignation is not done at exectime, modified virtual memory pagen muet be fushed as well. If done at exeatime, the procen's arguments and environment variables are tranderred. The esecs were performed with no open files. The bandwidth of the RPC aystem is $480 \mathrm{Kbyteo/second} \mathrm{aring} \mathrm{a} \mathrm{aingle} \mathrm{channel,} \mathrm{and} 660 \mathrm{Kby}$ tes/eccond using multiple RPC connections in peralle for the virtual memory aystem.

\section{Migration Overhead}

Table 1 summarizes the coots aeciated with migration. Hoat relection on SPARCstation 1 workstations takes an average of 36 milliseconds. Process tranfer is a function of some fixed overhead, plus variable overhead in proportion to the number of modified virtual memory pages and file blocks copied over the network and the number of files the process bas open. If a proceas execs at the time of migration, as is normally the case, no virtua memory in traneferred.

The costs in Table 1 reflect the latency and bandwidth of Sprite's remote procedure call mechenism. For example, the cost of transferring open files is dominated by RPC latency (3 RPC's at 1 ms latency each), and the speed of tranaferring virtual memory pagea and file blocks in determined by RPC bandwidth (480-660 Kbytes/second). All things considered, it takes sbout a tenth of a recond to select an idle host and start a new procea on it, not counting any time needed to tranefer open files or flush modified file blocks to cervers. Empirically, the average time to perform an exec-time migration in our nystem is about 330 millieconda 22 This latency may be too great to warrant running trivial programs remotely, but it is subatantially lea than the time needed to compile typical source programs, run text formatters, or do any number of other CPU-bound takk.

After a proceas migrates away from its bome machine, it may oufter from the overhead of forwarding system calls. The degradation due to remote execution depends on the ratio of locationdependent syatem calle to other operatione, web as computation and file 1/O. Figure 3 showe the total execution time to run eeveral program, linted in Table 2, both entirely locally and entirely on a single remote hoot. Applications that communicate frequently with the home machine suffered considerable degradation. Two of the benchmarks, fork and gettime, are contrived examples of the type of degradation a process might experience if it performed many location-dependent system calls without much user-level computation. The rep benchmark is a more realistic example of the penalties processes can encounter: it copies dats using TCP, and TCP operations are sent to a user-level 


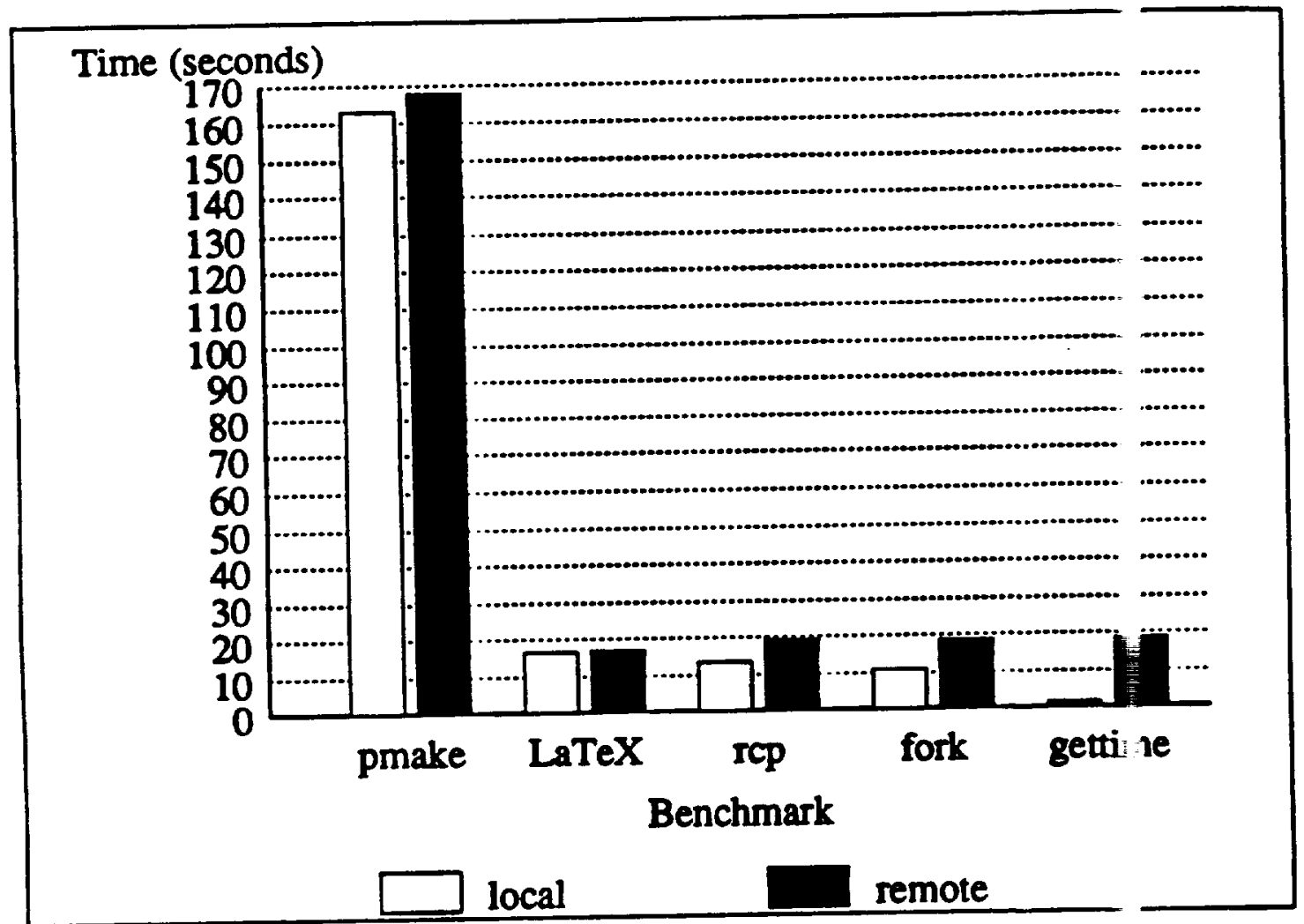

Figure 3: Comparison between local and remote execution of programs. The elapaed t ne to execute CPU-intensive and file-intensive applications such a pmake and ST $_{\mathrm{F}} \mathrm{X}$ ahowed negligible effe to from remote execution ( $3 \%$ and $1 \%$ degradation, respectively). Other applications enfiered performance fanaltiea meging from $42 \%$ (rcp), to $73 \%$ (fork), to $3200 \%$ (gettime).

\begin{tabular}{|c|c|}
\hline Name & Deacription \\
\hline pmake & recompile pmake source equentially using pmake \\
\hline $\mathrm{WT}_{\mathrm{E} X}$ & run UT $_{\mathrm{g}} \mathrm{X}$ on a draft of this article \\
\hline rep & copy a 1 Mbyte fle to another host uning TCP \\
\hline fork & fork and wait for child, 1000 times \\
\hline gettime & get the time of day 10000 times \\
\hline
\end{tabular}

Table 2: Workload for comparisons between local and remole execution. 
TCP server on the home machine. Forwarding these TCP operations causes rep to perform about $40 \%$ more slowly when run remotely than locally. As may be een in Figure 3, however, applications such as compilations and text formatting ahow little degradation due to remote execution.

\section{Application Performance}

The benchmarks in the previous section measured the component conts of migration. This section measures the overall benefits of migration using pmeke. We measured the performance improvernents obtained by parallel compilations and aimulations.

The first benchmark consists of compiling 276 Sprite kernel cource filea, then linking the reaulting object files in to a single file. Each pmake command (compiling or linking) is performed on a remote host using exec-time migration. Once a hoet is obtained from the pool of available hosts, it is reused until pmake finishes or the bost is no longer available.

Figure 4 shows the total elapsed time to compile and link the Sprite kernel using a varying number of machines in parallel, as well as the performance improvement obtained. In this environment, pmake is able to make effective use of about three-fourth of each host it uees up to a point (4-6 hosts), but it uses only balf the proceasing power available to it once additional hoots are used.

The "compile and link" curve in Figure 4(b) shows a speed-up factor of 5 uning 12 hoots. Clearly, there is a significant difference between the speed-upa obtained for the "normalized compile" benchmark and the "compile and link" benchmark. The difference in partly attributable to the requential parts of running pmake: determining file dependencies and linking object files all must be done on a single host. More importantly, file caching affects speed-up subetantially. As deacribed above, when a host opens a file for which another host is caching modified blocks, the host with the modified blocks transfers them to the server that atores the file. Thus, if pmake ues many hoats to compile different files in parallel, and then a single host links the resulting object files together, that bost must wait for each of the other hoets to fush the object files they created. It then munt obtain the object files from the server. In this case, linking the filea together when they have all been created on a single host takes only 56 seconds, but the link step takes 65-69 seconds when multiple hosts are used for the compilations.

In practice, we don't even obtain the five-fold speed-up indicated by this benchmark, becaure we compile and link each kernel module eeparately and link the modules together afterwarda. Each link step is an additional synchroniration point that may be performed by only one host at a time. In our development environment, we typically cee three to four times opeed-up when rebuilding a kernel from ecratch. Table 3 presents come examples of typical pmake opeed-upe. These times are representative of the performance improvemente ceen in day-to-day use. Figure 5 showe the corresponding speedup curves for each set of compilations when the number of hosts used varies from 1 to 12. In each case, the marginal improvement of additional bosts decreases as more boets are added.

The speedup curves in Figure 4 (b) and Figure 5 show that the marginal improvement from using additional hosts is significantly les than the processing power of the hosts would suggest. The poor improvement is due to bottlenecks on both the file server and the workstation running 


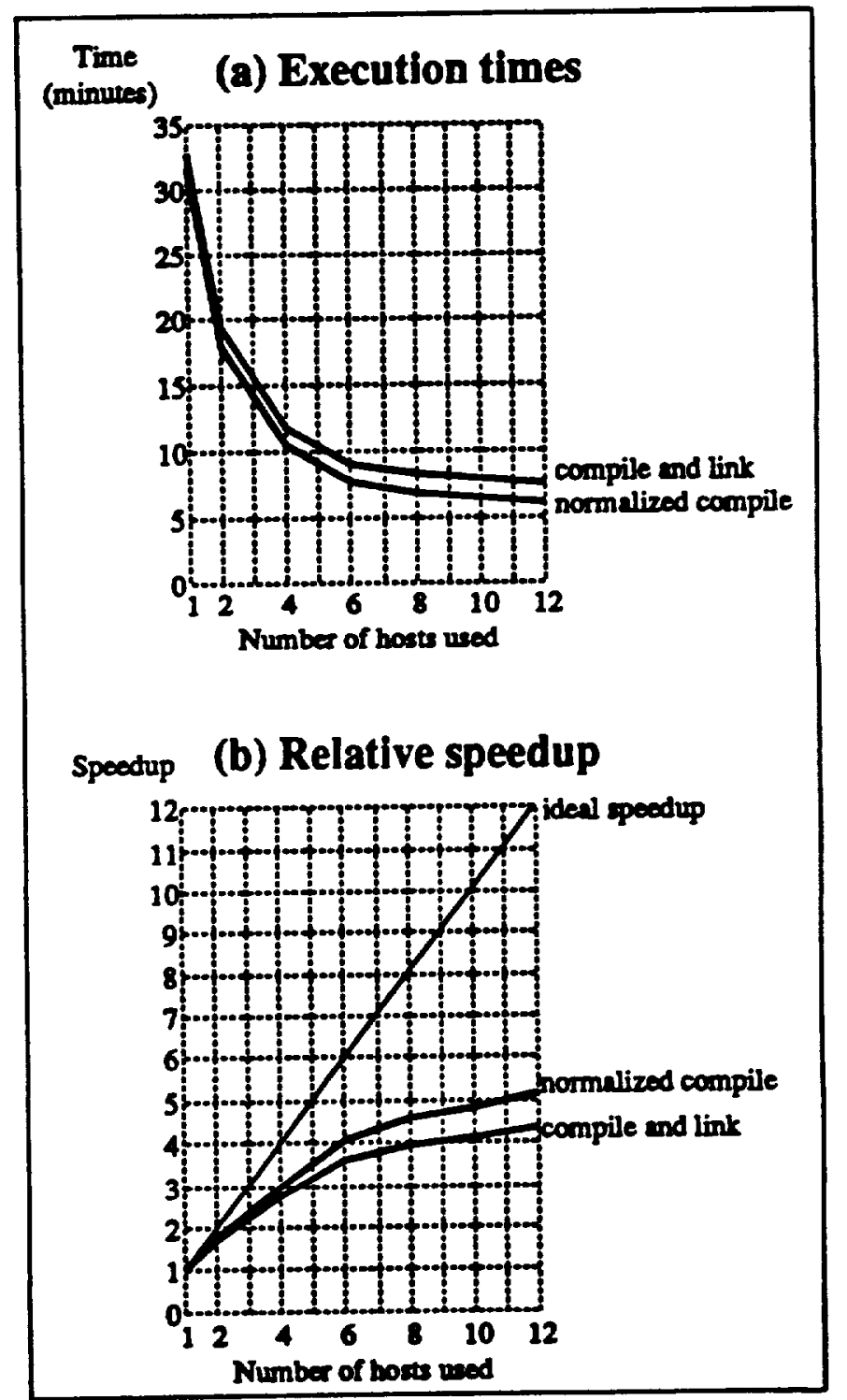

Figure 4: Performance of recompiling the Sprite kernel wing a varying number of hosts ad the pmake program. Graph (a) show the time to compile all the input Allea and then link the realting sbjoct flee in to angle file. In addition, it ohow a "normalized" carre that shom the time taken for the c-mpilation only, deducting as well the pmake etartop overhead of 19 meconds to determine dependenciex; this arve represents the parallelizable portion of the pmake beachmark. Gnph (b) shows the opeedup obtained sor each point in (a), which is the ratio between the time taken or a ingle hoot and the time using multiple 1 onts in parallel. 


\begin{tabular}{|c|c|c|c|c|c|}
\hline Program & $\begin{array}{l}\text { Num } \\
\text { Files }\end{array}$ & $\begin{array}{l}\text { Der of } \\
\text { Link }\end{array}$ & Sequential Time & Parallel Time & Speed-Up \\
\hline gremlin & 24 & 1 & 180 & 41 & 4.43 \\
\hline$T_{E} X$ & 36 & 1 & 259 & 48 & 5.42 \\
\hline pmake & 48 & 3 & 162 & 55 & 2.95 \\
\hline kernel & 276 & 1 & 1971 & 453 & 4.35 \\
\hline
\end{tabular}

Table 3: Examples of pmake performance. Sequential execution is done on a single hoat; parallel execr tion uses migration to execote up to 12 takks in parallel. Each mearurement pives the time to compile the indiated number of files and link the resulting object fles together is one or more stepe. When multiple rtepe are required, their sequentinlity reduces the speed-np that may be obtained; pmake, for example, in organized into two directories that are compiled and linked sepantely, and then the two linked object files are linked together.

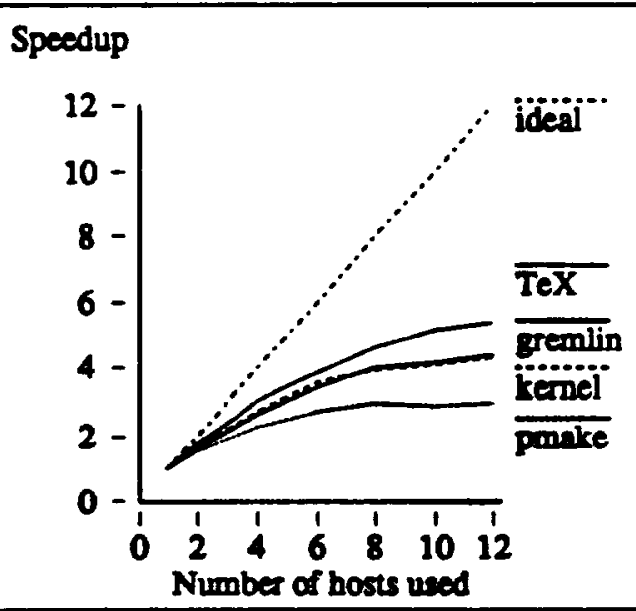

Figure 5: Speedup of compilations using a variable number of hosts. This grnph obows the speedup relative to running pmake on one hont (i.e., without migretion). The speedup obtrined depends on the extent that hosts can be kept busy, the amount of parallelization anilable to prnake, and syatem bottlenecka. 


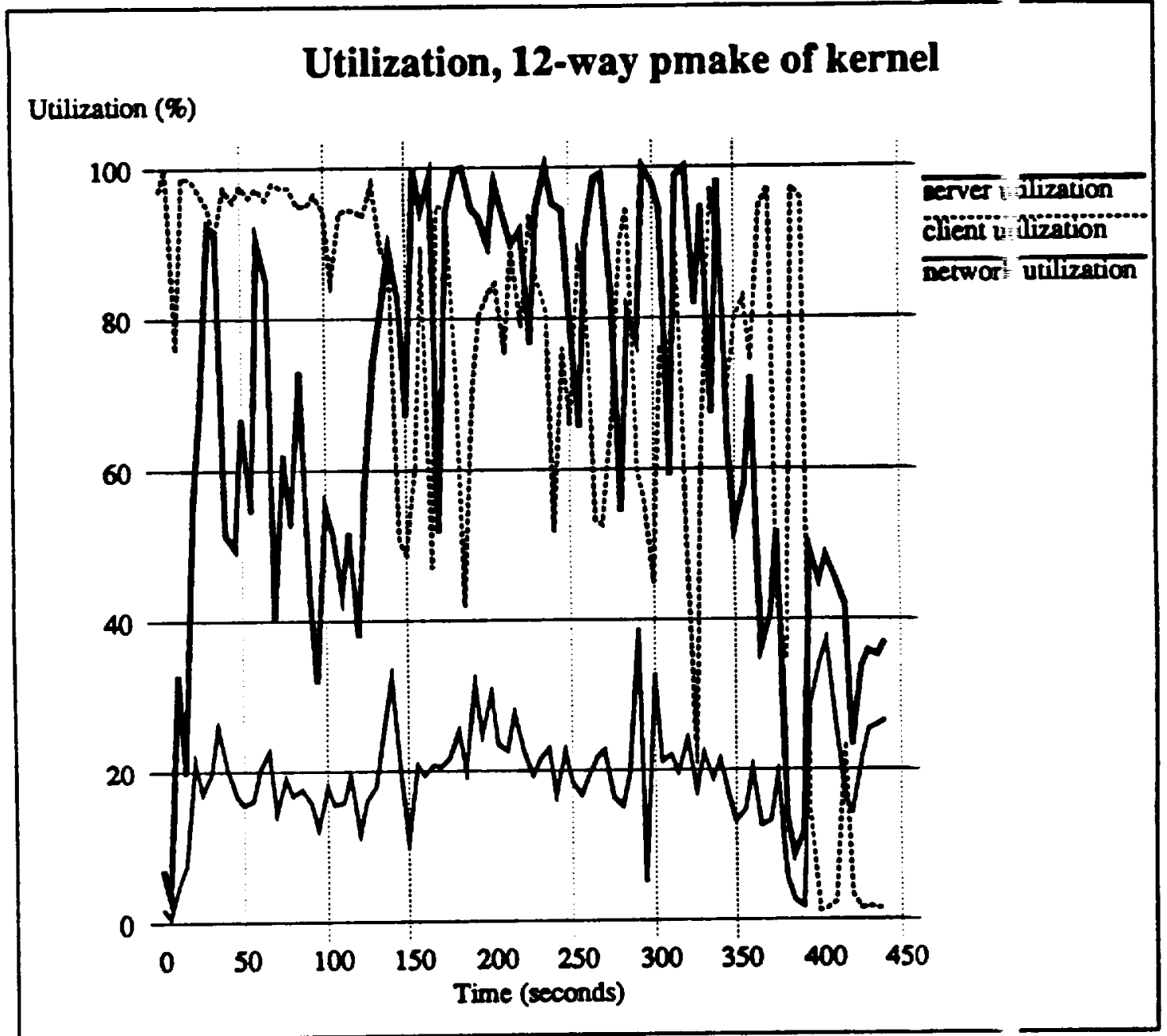

Figure 6: Processor and network utilization during the 18-woy pmake. Both the file serve and the client workstation running pmake were mturated.

pmake. Figure 6 shows the utilization of the processors on the file server and client $n$,rkatation over 5-second intervals during the 12-way kernel pmake. It show that the pmake proc unes nearly $100 \%$ of a SPARCstation processor while it determines dependencies and starts to $m$ jate procences to perforin compilation. Then the Sun- $1 / 280$ file nerver's processor becomes a bottl neck as the 12 hosts performing compilations open files and write back cached object filea. The net: ork utilization, also shown in Figure 6, averaged around $20 \%$ and is thus not yet a problem. Howeve, whe therver and client procesers get faster, the network may easily become the next bottleneck

Though migration has been uned in Sprite to perform compilations for nearly to o yeara, it has only recently been ueed for more wide-ranging applicatione. Excluding compilatio a, simulations are the primary application for Sprite's process migration facility. It is now comm in for users to use pmake to run up to one hundred aimulations, letting pmake control the paralleli: $m$. The length and parallelism of simulations reaults in more frequent evietions than occur with mo compilations, and pmake automatically remigrates or suspends processes subsequent to eviction. 


\begin{tabular}{|l|c|c|c|}
\hline \multicolumn{1}{|c|}{ Host } & Total CPU Time & Remote CPU Time & Fraction Remote \\
\hline garlic & 314,218 recs & 228,641 recs & $72.77 \%$ \\
\hline crackle & 172,355 & 14,451 & $8.38 \%$ \\
\hline cassafras & 158,515 & 138,821 & $\mathbf{8 7 . 5 8 \%}$ \\
\hline burble & 151,117 & 2,352 & $1.56 \%$ \\
\hline vagrancy & 107,853 & 81,343 & $75.42 \%$ \\
\hline buzz & 96,402 & 260 & $0.27 \%$ \\
\hline cage & 92,063 & 32,525 & $35.33 \%$ \\
\hline kvetching & 01,611 & 26,765 & $29.22 \%$ \\
\hline jaywalk & 75,394 & 24,017 & $31.86 \%$ \\
\hline joyride & 58,231 & 6,233 & $10.70 \%$ \\
\hline \hline Others & 857,532 & 120,727 & $14.1 \%$ \\
\hline \hline Total & $2,175,291$ & 676,135 & $31.08 \%$ \\
\hline \hline
\end{tabular}

Table 4: Remote procesaing use over a one-month period The ten hosts with the greateat total procesuor nage are shown individually. Sprite hosts performed roughly $30 \%$ of aser sctivity aring proces migretion. The standard deviation of the frection of remole nee wa $25 \%$.

In addition to having a longer average execution time, simulations also cometimes differ from compilations in their use of the file system. While some simulators are quite $1 / O$ intensive, others are completely limited by processor time. Because they perform minimal interaction with file cervers and use little network bandwidth, they can acale better than parallel compilations do. One set of simulations obtained over $800 \%$ effective processor utilization-eight minutes of proceaning time per minute of elapsed time-over the course of an hour, using all idle hosts on the aystem (up to 10-15 bosts of the same architecture).

\section{Usage Patterns}

We instrumented Sprite to keep track of remote execution, migrations, evictions, and the availability of idle hosts. First, when a process exited, the total time during which it executed wae added to a global counter; if the process had been executing remotely, its time was added to a eeparate counter as well. (These counters therefore excluded some long-running proceses that did not exit before a bost rebooted; however, these proceses were daemon, display cervera, and otber procesces that would normally be unsuitable for migration.) Over a typical one-month period, remote processes accounted for about 31\% of all processing done on Sprite. One boat ran applicatione that made much greater use of remote execution, executing w much $a 88 \%$ of user cycles on other hosts. Table 4 lists some sample proceseor uage over this period.

During the same time frame, we recorded the frequency of exec-time migrations and full migretions in order to determine the most common usage of the migration facility. Since full migrations require that virtual memory be copied, the choice of a virtual memory tranofer method would be important if full migrations occurred relatively often. In the one-month period studied, ezec-time migrations occurred at a rate of $1.76 /$ hour/host over that period, constituting $86 \%$ of all migrations.

Second, we recorded each time a hout changed from idle to aetive, indicating that foreign processes would be evicted if they exist, and we counted the number of times evietions actually occured. 


\begin{tabular}{|l|c|c|c|}
\hline Time Frame & In Use & Idle & for Migration \\
\hline weekdays & $31 \%$ & $66 \%$ & $3 \%$ \\
\hline off-hours & $20 \%$ & $78 \%$ & $2 \%$ \\
\hline total & $23 \%$ & $75 \%$ & $2 \%$ \\
\hline
\end{tabular}

Table 5: Host availability. Weekdays are Monday throngh Frides from 0:00 A.M. to 5:00 I M. Off-houre are all other times.

To date, evictions have been extremely rare. On the average, each host changed to th active state only once every 26 minutes, and very few of these transitions actually resulted in pr cesses being evicted ( 0.12 processes per bour per host in a collection of more than 25 bosto). Th infrequency of evictions bas been due primarily to the policy ued for allocating hoste: hoste ar ansigned in decreasing order of idle time, 20 that the hosts that have been idle the longest are us $d$ most often for migration. The average time that hosts had been idle prior to being allocated fo remote execution was 17 hours, but the average idle time of thooe houts that later evicted proci-aes was only 4 minutes. (One may therefore asoume that if hosts were allocated randomly, rather han in order of idle time, evictions would be considerably more frequent.) Finally, when evictions id occur, the time needed to evict varied considerably, with a mean of 3.0 eeconds and a standar: deviation of 3.1 seconds to migrate an average of 3.3 proceses. An average of 374 Kbyte page: were written per process that migrated, with a standard deviation of 6.5 from hoat to bost.

Third, over the course of over a year, we periodically recorded the atate of ever. hoot (active, idle, or hosting foreign processes) in a log file. A surprisingly large number (66-78\%, of hoots are available for migration at any time, even during the day on weekdays. This is par $y$ due to our environment, in which several users own both a Sun and a DECatation and use o: ly one or the other at a time. Some workstations are available for public use and are not used on E regular basis. However, after discounting for extra workstations, we still find a sizable fraction of $y$ wots available, concurring with Theimer, Nichole, and others. Table 5 eummarizes the availability of oats in Sprite over this period.

To further study the availability of idle hoots, we recorded information about re fueste for idle hosts over a 25-day period. During this period, over 17,000 processes requested or ; or more idle hosts, and $86 \%$ of those proceases obtained as many bosts as they requeated. Only 276 of proceses were unable to obtain any hoats at all. Procewes requented an average of 2.6 houts, ith a standard deviation of 4.58 hosts and $76 \%$ of proceseses requesting at most one hoat at $a$ time. S ace there were typically 10 or more idle machines available for each machine type, one would expect procesees that request few bosts to be able to obtain them; more intereatingly, however, over $80 \%$ of thome hosts requesting at least 10 bosts were able to obtain 10 bonts. Figure 7 ahows the fract of of procences during this period that received a many hoots as requeated, a a cumulative function of the number of hosts requested. 


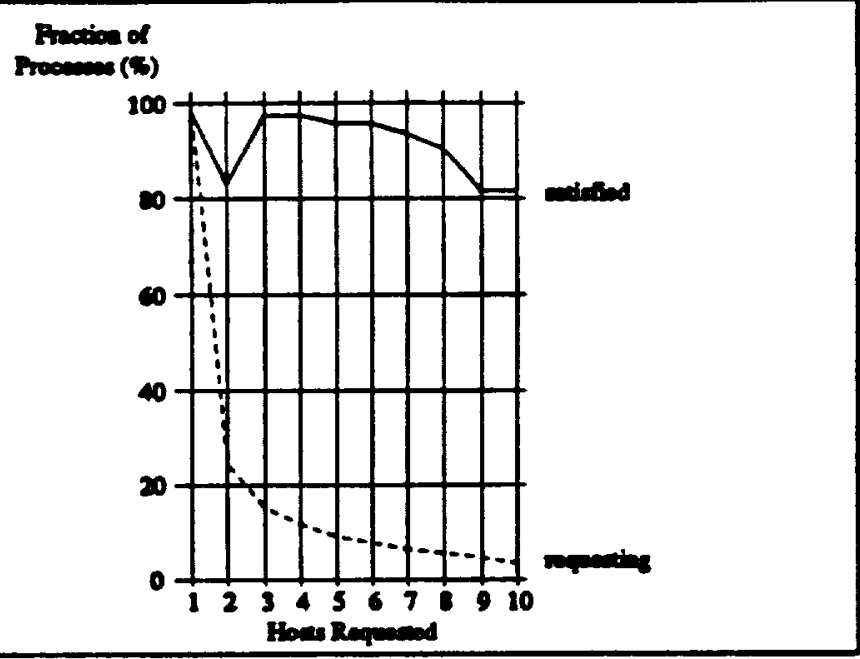

Figure 7: Distribution of host requests and satisfaction rates. For a given number of hoste, ahown on the $X$-axis, the line labeled requesting show the frection of proceses that requeated at leart that many houts. The line labeled eatisfied shows, ont of those processes that requested at least that anmber of houts, the fraction of processes that evccessfully obtained that many hosts. Thw, $98 \%$ of all procesces were able to obtain at least one host, and over $80 \%$ of proceses that requested at least ten hosts obtained 10 hosts. Only $24 \%$ of procesese requested more than one host.

\section{Observations}

Based on our experience, as well a those of others ( $V$; Charlotte, and Accent ${ }^{\text {17}}$ ), we have observed the following:

- The overall improvement from using idle hosts can be substantial, depending upon the degree of parallelism in an application.

- Remote execution current accounts for a airable fraction of all proceaning on Sprite. Even wo, idle bosts are plentiful. Our use of idle hoots is currently limited more by a lack of applications (other than pmake) than by a lack of bosts.

- The cost of exec-time migration is high by comparieon to the coat of local proceas creation, but it is relatively amall compared to times that are noticeable by humans. Furthermore, the overhead of providing transparent remote execution in Sprite is negligible for moet elanes of processes. The system may therefore be liberal about placing procesces on other hoots at exee time, as long as the likelihood of eviction is relatively low.

- The cost of transferring a process's address space and tlushing modified file blocks dominates the cost of migrating long-running procesesen, thereby limiting the effectivenea of a dynamic "pool of processon" approsch. Although there are other environments in which such an approach could have many favorable aspects, given our asumptions above about hoot availability and workstation "ownership", using process migration to belance the load among all Sprite hosts would likely be both unnecessary and undesirable. 


\section{History and Experience}

The greatest lesson we have learned from our experience with process migration is ibe old adage "use it or lose it." Although an experimental version of migration was operational in 186, 23 it took another two years to make migration a useful utility. Part of the problem was that a w important mechanisms weren't implemented initially (e.g., there was no automatic bout selection, rigration was not integrated with pmake, and procese migration did not deal gracefully with mac ine crashes). But the main problem was that migration continually broke due to other changes in the Sprite kernel. Without regular use, problems with migration weren't noticed and tended t. accumulate. As a result, migration was only ueed for occanional experiments. Before each exper nent a major effort was required to fix the accumulated problems, and migration quickly broke ain after the experiment was finished.

By the fall of 1988 we were beginning to mupect that migration was too fragile to be naintainable. Before abandoning it we decided to make one last push to make process migration con: letely usable, integrate it with the pmake program, and use it for long enough to underetand its ber fits as well as its drawbacks. This was a fortunate decision. Within one week after migration becar e available in pmake, other members of the Sprite project were happily using it and achieving spee -up factors of two to five in compilations. Because of its complex interactions with the rest of the ke jel, migration is still more fragile than we would like and it occasionally breaks in response to ot er changes in the kernel. However, it is used 20 frequently that problems are detected immediatel: and they can usually be fixed quickly. The maintenance load is atill higher for migration than $f$ i many other parts of the kernel, but only slightly. Today we consider migration to be an indispi Lable part of the Sprite system.

We are not the only ones to have had difficulties keeping process migration runnin : for example, Theimer reported similar experiences with his implementation in V. The proble 1 seems to be inherent in migration, since it interacts with many other parts of the kernel. In $S$ rite the most complicated aspects of migration were those related to migrating open files. In par cular, locking and updating the data structures for an open file on multiple hosts provided numerov opportunities for distributed deadlocks, race conditions, and inconsistent reference counts. It is $w$ - rth reiterating that these problems would have been present even if we had chowen to implement a "i mpler" remote invocation facility without procese migration.

\section{Conclusions}

Process migration is now taken for granted as an esential part of the Sprite nye em. It is used bundreds of times daily and provides subatantial apeed-upe for applications that a amenable to coarse-grain parallel processing, wuch $\boldsymbol{n}$ compilation and aimulation. The transpe ency provided by the migration mechanism makes it eary to use migration, and eviction keepe igration from bothering the people whose machines are borrowed. Collectively, remote executior accounts for a sizable portion of all user activity on Sprite.

We were originally very conservative in our use of migration, in order to gain ac ptance among our users. As time bas passed, our users have become accustomed to their worksta ons being used 
for migration and they have gained confidence in the eviction mechaniam. We have gradually become more liberal about using idle machines, and we are experimenting with new system-wide migration tools, such as command shells that automatically migrate some task (e.g., jobs run in beckground). So far our users have appreciated the additional opportunities for migration and have not perceived any degradation in their interactive respone.

From the outset we expected migration to be difficult to build and maintain. Even $\infty$, we were ourprised at the complexity of the interactiona between proceas migration and the reat of the kernel, particularly where distributed atate wa involved a with open files. It was interesting that Sprite's network file system both simplified migration (by providing transparent remote access to files and devices) and complicated it (because of the file aystem's complex diatributed atate). We believe that our implementation has now reached a stable and maintainable state, but it bas taken us a long time to get there.

For us, the bottom line is that process migration is too useful to pass up. We encourage others to make process migration available in their aystems, but to beware of the implementation pitfalls.

\section{Acknowledgments}

In addition to acting as guines pigs for the early unatable implementations of process migration, other members of the Sprite project have made significant contributions to Sprite's procea migration facility. Mike Nelson and Brent Weich implemented most of the mechaniom for migrating open files, and Adam de Boor wrote the pmake program. Liea Bahler, Thoraten von Eicken, John Hartman, Darrell Long, Mendel Rosenblum, and Ken Shirriff provided comments on early drafts of this paper, which improved the presentation substantially. We are also grateful to the anonymous referces of Software Practice \& Experience, who provided valuable feedbeck and suggeations. Of course, any errors in this article are our responsibility alone.

\section{References}

1. D. Nichols. Using idle workstations in a shared computing environment. In Proceedings of the Eleventh ACM Symposium on Operating Syotems Principles, pages 5-12, Austin, TX, November 1987. ACM.

2. E. Roberts and J. Ellis. parmake and dp: Experience with a distributed, parallel implementation of make. In Proceedings from the Second Wortshop on Lerge-Greined Peralleliom. Software Engineering Institute, Carnegie-Mellon Univessity, November 1987. Report CMU/SEI-87-SR-5.

3. M. Theimer, K. Lantz, and D. Cheriton. Preemptable remote execution facilitie for the VSystem. In Proceedings of the 10th Symposium on Operating Syotem Principles, pages 2-12, December 1985.

4. E. Zayas. Attacking the procese migration bottleneck. In Proceedings of the Eleventh ACM Symposium on Operating Systems Principles, pages 13-22, Austin, TX, November 1987.

5. G. J. Popek and B. J. Walker, editors. The LOCUS Distributed Syatem Arehitecture. Computer Systems Series. The MIT Preas, 1985. 
6. A. Barak, A. Shiloh, and R. Wheeler. Flood prevention in the MOSIX bad-balan ing scheme. IEEE Computer Society Technical Committee on Opereting Syotems Newsletter. 3(1):23-27, Winter 1989.

7. S. I. Feldman. Make - a program for maintaining computer programs. Sofiware- 'ractice end Experience, 9(4):255-265, April 1979.

8. M. Theimer. Preemptable Remote Execution Facilities for Loosely-Coupled Distrib led Systems. $\mathrm{PhD}$ thesis, Stanford University, 1886.

9. Y. Artsy and R. Finkel. Designing a proces migration facility: The Charlotte expe ience. IEEE Computer, 22(9):47-56, September 1989.

10. J. K. Ousterbout, A. R. Cbereneon, F. Douglis, M. N. Neleon, and B. B. Welct The Sprite network operating system. IEEE Computer, 21(2):23-36, February 1988.

11. M. Nelson, B. Welch, and J. Ousterbout. Caching in the Sprite network file stem. $A C M$ Transactions on Computer Systems, 6(1):134-154, February 1988.

12. A. D. Birrell and B. J. Nelson. Implementing remote procedure calls. ACM Tr nsactions on Computer Systems, 2(1):39-59, February 1984.

13. Computer Science Division, University of Californie, Berkeley. UNIX User's Refe- nce Manual, 1.9 Berkeley Software Distribution, Virtwal VAX-11 Version, April 1986.

14. M. Litzkow. Remote UNIX. In Proceedinge of the USENIX 1987 Summer Co: Perence, June 1987.

15. M. Accetta, R. Baron, W. Bolosky, D. Golub, R. Rashid, A. Tevanian, and M. oung. Mach: A new kernel foundation for UNIX development. In Proceedinge of the USENIX 1986 Swmmer Conference, July 1986.

16. D. R. Cheriton. The V distributed system Communications of the ACM, 31(3):3 1-333, March 1988.

17. E. Zayas. The Use of Copy-On-Reference in a Process Migration System. PhD t sis, Carnegie Mellon Univeraity, Pitteburgh, PA, April 1987. Report No. CMU-CS-87-121.

18. K. Li and P. Budak. Memory coherence in shared virtual memory systems In Proceedings of the 5th ACM Symposium on Principles of Distributed Computing, pages 229-238. ACM, Auguat 1986.

19. D. L. Eager, E. D. Lacowaka, and J. Zahorjan. The limited performance benefi: 1 of migrating actlve processes for load sharing. In ACM SIGMETRICS 1088, May 1988.

20. D. L. Eager, E. D. Lacowaka, and J. Zahorjan. Adaptive load aharing in homogene us diatributed systems. IEEE Transactions on Sofiware Engineering, SE-12(5):662-675, May 186.

21. E. H. Bealbergen. Parallel and distributed compilations in loosely-coupled sy tems: A case study. In Proceedinge of Workshop on Large Grain Paralleliom, Providence, RI, Jctober 1986. 
22. F. Douglis. Transparent Process Migration in the Sprite Opereting Syotem. PhD theais, University of California, Berkeley, CA 94720, September 1090. A vailable as Technical Report UCB/CSD 90/598.

23. F. Douglis and J. Ousterhout. Process migration in the Sprite operating system. In Proceedings of the Th International Conference on Dirtributed Computing Syotema, pages 18-25, Berlin, West Germany, September 1987. IEEE. 